\title{
Cell-bound peptidase activities of Treponema denticola ATCC 33520 in continuous culture
}

\author{
F. H. M. Mikx, ${ }^{*}$ F. Jacobs and C. Satumalay \\ Department of Periodontology and Preventive Dentistry, TRIKON, University of Nijmegen, PO Box 9101, \\ NL-6500 HB Nijmegen, The Netherlands
}

(Received 24 February 1992; revised 1 June 1992; accepted 16 June 1992)

\begin{abstract}
The oral spirochaete Treponema denticola ATCC 33520 was grown at a mean generation time of $10 \mathrm{~h}$ in anaerobic continuous culture in a serum- and carbohydrate-free medium at $\mathrm{pH} 7.0$. The extracellular proteolytic activities of this spirochaete were then investigated by incubating washed cells with 68 2-naphthylamide derivatives of the Extended API System. Chymotrypsin-like, trypsin-like, elastase-like and iminopeptidase activities were demonstrated. The phenylalanine peptidase or chymotrypsin-like activity of $T$. denticola ATCC 33520, estimated with $\boldsymbol{N}$-succinyl-L-phenylalanyl-L-leucyl-L-phenylalanine-thiobenzyl ester (SPLP) had a pH optimum at pH 8.5, a specific activity of $36.6 \mathrm{nmol} \mathrm{min}{ }^{-1}\left(\mathrm{mg}\right.$ dry wt) ${ }^{-1}$ and was inhibited only slightly by $\mathrm{HgCl}_{2}$. The trypsin-like activity, estimated with benzoyl-DL-arginine-7-amido-4-methylcoumarin (BAMC), had a pH optimum at pH 9, and a specific activity of $0.3 \mathrm{nmol} \mathrm{min}^{-1}\left(\mathrm{mg}\right.$ dry wt) ${ }^{-1}$; inhibition by $\mathrm{HgCl}_{2}$ indicated the involvement of active thiol groups. The activity should preferably be termed arginine peptidase activity, according to the carboxyterminal amino acid of the test substrate. The extracellular proline peptidase activity, estimated with L-proline-7amido-4-methylcoumarin. $\mathrm{HBr}$ (PRAMC), had an activity of $1.5 \mathrm{nmol} \mathrm{min}^{-1}\left(\mathrm{mg} \mathrm{dry} \mathrm{wt}^{-1}\right.$, an optimum at pH 8.5 and the properties of a thiol protease. The main cell-bound and extracellular active peptidase activities of fastgrowing cells of $T$. denticola ATCC 33520 are phenylalanine peptidase, proline peptidase, arginine peptidase and an oligopeptide-dependent alanine peptidase activity. The cell-bound peptidase activities are of potential importance for invasion and multiplication in the junctional epithelium and the destruction process in periodontal pockets with an anaerobic and alkaline environment.
\end{abstract}

\section{Introduction}

Treponema denticola is one of the oral spirochaetes associated with periodontal disease (Listgarten \& Hellden, 1978; Armitage et al., 1982; Loesche, 1988). T. denticola has endo- and exopeptidase activities and is the most proteolytic species of the genus Treponema (Mikx, 1991). Of the oral flora, T. denticola and Porphyromonas gingivalis show proteolytic activities, a characteristic probably related to their virulence and used in the diagnosis of periodontal disease (Laughon et al., 1982; Syed et al., 1984; Loesche et al., 1990). T. denticola is able to degrade type IV collagen, gelatin, elastin and fibronectin (Uitto et al., 1986). These proteolytic activities are considered of importance for the acquisition of nitrogenous growth substances, the perturbation of the host defenses, invasion and multiplication in the junctional epithelium (Saglie et al., 1982; Uitto et al., 1988a; Mikx et al., 1990; Reijntjens et al., 1986).

* Author for correspondence. Tel. 80 614049; fax 80541314.
Trypsin-like, chymotrypsin-like, iminopeptidase and keratinolytic activities of $T$. denticola have been demonstrated by different investigators (Ohta et al., 1986; Fiehn, 1986; Mäkinen et al., 1986, 1987; Mikx \& de Jong 1987; Syed et al., 1988). Recently Grenier et al., (1990) demonstrated the location of a chymotrypsin-like enzyme at the outside of the cell envelope of $T$. denticola.

Most studies of the different proteases of $T$. denticola have been performed with purified cell extracts of batchgrown spirochaetes. In the present study, the extracellular proteolytic activities of intact and relatively fastgrowing $T$. denticola cells were investigated. A selection of synthetic substrates was made and the $\mathrm{pH}$ optima and specific activities of cell-bound arginine, phenylalanine and proline peptidases were estimated. In order to control growth and substrate effects, the spirochaetes were grown in continuous culture in a serum- and carbohydrate-free medium. In order to measure the activities of the same population, the cells were harvested, washed and tested simultaneously for the different activities. 


\section{Methods}

Continuous culture. Treponema denticola ATCC 33520 was grown in PTY broth, a serum- and carbohydrate-free medium, containing $1 \%$ (w/v) Proteose peptone no. 2, 0.5\% yeast extract (both from Difco), $0.5 \%$ Trypticase peptone (BBL), $0.25 \% \mathrm{KCl}, 0.05 \%$ L-cysteine, $25 \mathrm{mg}$ thiamin pyrophosphate $1^{-1}, 0.5 \mathrm{~g} \mathrm{NaH}_{2} \mathrm{CO}_{4}$, and isobutyric, DL-2methylbutyric, valeric and isovaleric acids (each $2.5 \mathrm{mg}^{-1}$ ). The medium was stored at room temperature and connected to the culture vessel under a continuous stream of $4 \%(\mathrm{v} / \mathrm{v}) \mathrm{CO}_{2}$ and $5 \%(\mathrm{v} / \mathrm{v}) \mathrm{H}_{2}$ in oxygen-free nitrogen. The dilution rate of the anaerobic continuous culture was $D=0.07 \mathrm{~h}^{-1}$, the $\mathrm{pH}$ and redox potential were continuously recorded and the culture vessel was kept at $37^{\circ} \mathrm{C}$. The cell mass from $40 \mathrm{ml}$ samples taken from the culture at steady state was estimated after washing the pellet twice in demineralized water by centrifugation $(15 \mathrm{~min}$ at $15000 \mathrm{~g})$ and drying at $100^{\circ} \mathrm{C}$. The fermentation products were measured by isotachophoresis in a LKB 2127 Tachophor. Samples for the enzyme activity measurements were taken directly from the culture vessel, and washed by centrifugation and resuspension in the indicated buffer.

$N$-acetyl arylamidase activities. The Extended API System and API ZYM were used to test the activity of $T$. denticola ATCC 33520 cells on 68 different amino-, dipeptide- and oligopeptide naphthylamide derivatives. Suspensions of the spirochaetes $\left(\mathrm{OD}_{550} 2\right)$ in $0.1 \mathrm{M}$ potassium phosphate buffer, $\mathrm{pH} 7.0$, were added to the cupules of the API research kits, incubated aerobically for $4 \mathrm{~h}$ at $37^{\circ} \mathrm{C}$ and evaluated according to the manufacturer's instructions as previously described (Mikx, 1991).

Arginine aminopeptidase activity. A mixture of $2 \mathrm{ml} 0.25 \mathrm{~mm}-\mathrm{N}$ benzoyl-L-arginine-ethyl ester (BAEE; Sigma) and $2 \mathrm{ml}$ of spirochaete suspension $\left(\mathrm{OD}_{550} 0.85\right)$ in $0.1 \mathrm{M}$-potassium phosphate buffer, $\mathrm{pH} 7.5$, was incubated at $37^{\circ} \mathrm{C}$ for $90 \mathrm{~min}$. After incubation and centrifugation the absorbance at $253 \mathrm{~nm}$ was measured in a Zeiss PMQ 3 spectrophotometer. In the control mixtures the substrate or the spirochaetes were omitted.

When testing different spirochaete densities, the reaction mixture was $2 \mathrm{ml}$ of spirochaete suspension in $0.1 \mathrm{M}$-Tris/ $\mathrm{HCl}$ buffer, $\mathrm{pH} 8.0$, and $50 \mu \mathrm{l} 0 \cdot 1 \mathrm{M}-\mathrm{N}$-benzoyl-DL-arginine-naphthylamide. $\mathrm{HCl}$ (BANA, Sigma) in dimethylsulphoxide (DMSO). Samples were taken at the start and after incubation at $37^{\circ} \mathrm{C}$ for various times, centrifuged and measured in a Zeiss PMQ3/ZFM4 Spektralfluorometer, excitation $335 \mathrm{~nm}$, emission $410 \mathrm{~nm}$.

The optimum concentration of benzoyl-DL-arginine-7-amido-4methylcoumarin. $\mathrm{HCl}$ (BAMC; Bachem, Bubendorf, Switzerland) was estimated with $1 \mathrm{ml}$ of spirochaete suspension $\left(\mathrm{OD}_{550} 0 \cdot 128\right)$ in $0.1 \mathrm{M}$ Tris/ $\mathrm{HCl}$ buffer, $\mathrm{pH} 8.0$, and 1 to $80 \mu \mathrm{l}$ of a stock solution of $32 \mathrm{mM}$ BAMC in DMSO. After $45 \mathrm{~min}$ incubation at $37^{\circ} \mathrm{C}$ the reaction was stopped by transferring a $40 \mu \mathrm{l}$ sample to $1 \mathrm{ml}$ of demineralized water at $4{ }^{\circ} \mathrm{C}$. The fluorescence was measured in a Perkin Elmer LS5 luminescence spectrophotometer, excitation $370 \mathrm{~nm}$, emission $460 \mathrm{~nm}$. The effect of different spirochaete densities on BAMC degradation was estimated with $0.32 \mathrm{~mm}$-BAMC in $0.1 \mathrm{Tris} / \mathrm{HCl}$ buffer, $\mathrm{pH} 8.0$.

The $\mathrm{pH}$ optimum was estimated in two experiments done in duplicate with $1 \mathrm{ml}$ of spirochaete suspensions $\left(\mathrm{OD}_{550} 0.05\right)$ in Teorell and Stenhagen's $1 \mathrm{~mm}$-citrate/10 mM-phosphate $/ 20 \mathrm{~mm}$-borate buffer over the pH range pH 6.0 to $\mathrm{pH} 12$ (Sober, 1970); $10 \mu 1$ BAMC stock solution was added and the mixture was incubated at $37^{\circ} \mathrm{C}$ for $60 \mathrm{~min}$.

The specific activity for BAMC was estimated in two experiments done in triplicate by incubating a spirochaete suspension $\left(\mathrm{OD}_{550} \mathbf{0 . 0 5}\right)$

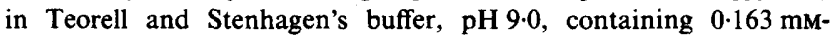
BAMC for $30 \mathrm{~min}$ at $37^{\circ} \mathrm{C}$. The reactions were stopped in demineralized water at $4{ }^{\circ} \mathrm{C}$ as previously described. In the same set of tests the effect of 2 mM-dithiothreitol (DTT), 2 mM-phenylmethylsulphonyl fluoride (PMSF) or $0.5 \mathrm{mM}-\mathrm{HgCl}_{2}$ in the reaction mixture was measured. Calibration curves of coumarin and fluorescence and of spirochaete density $\left(\mathrm{OD}_{550}\right)$ and dry weight were used for calculating specific activities.

Phenylalanine aminopeptidase activity. The tests with $2.5 \mathrm{mM}-$ benzyloxycarbonyl-L-phenylalanine-2-naphthylamide (PHENA) and $\quad 0.32 \mathrm{mM}$-glutaryl-phenylalanine-7-amido-4-methylcoumarin (PHAMC) were carried out under the same conditions and in the same experiments as described for BANA and BAMC.

The pH optimum was estimated in two experiments done in duplicate with $N$-succinyl-L-phenylalanyl-L-leucyl-L-phenylalaninethiobenzyl ester (SPLP; Bachem) according to Harper et al. (1981). The reaction mixture, comprising $0.9 \mathrm{ml} 0.237 \mathrm{mM}$-SPLP, $75 \mu 10.86 \mathrm{~mm}$ dithiopyrimidine (DTP) and $50 \mu \mathrm{l}$ of spirochaete suspension $\left(\mathrm{OD}_{550}\right.$ 0.5 ), all in Teorell and Stenhagen's buffer with $10 \%$ DMSO, was incubated at $20^{\circ} \mathrm{C}$ for $30 \mathrm{~min}$. The reaction product, 4-thiopyridone, was measured at $324 \mathrm{~nm}$. In the same manner, the specific activity at pH 8.5 and the effect of $2 \mathrm{mM}-\mathrm{PMSF}$ and $0.5 \mathrm{mM}-\mathrm{HgCl}_{2}$ were estimated. The specific activity was calculated using the results of two experiments in triplicate and the extinction coefficient for 4thiopyridone $\left(\varepsilon=19800 \mathrm{M}^{-1} \mathrm{~cm}^{-1}\right)$.

Proline aminopeptidase activity. Benzyloxycarbonyl-L-proline (PRONA ; Bachem) (2.5 mM) and L-proline-7-amido-4-methylcoumarin. $\mathrm{HBr}$ (PRAMC; Bachem) $(0.125 \mathrm{mM})$ were tested under the same conditions as described for BANA and BAMC. The specific activity for PRAMC was estimated in two experiments in triplicate with spirochaete suspensions $\left(\mathrm{OD}_{550} 0.05\right)$ and $0.125 \mathrm{mM}$-PRAMC in Teorell and Stenhagen's buffer at $\mathrm{pH} 8.5$ and $37^{\circ} \mathrm{C}$. The effects of $0.5 \mathrm{mM}-\mathrm{HgCl}_{2}, 2 \mathrm{mM}$-DTT and $2 \mathrm{mM}$-PMSF were tested as described for BAMC

\section{Results}

\section{Activities of the continuous culture}

In the steady state, the continuous culture of $T$. denticola ATCC 33520 stabilized at $\mathrm{pH} 7 \cdot 0, E_{\mathrm{h}}-385 \mathrm{mV}$ and a $\mathrm{d}_{\mathrm{y}} \mathrm{y}$ wcight of $215 \mathrm{mg}^{-1}$. The main fermentation product was acetic acid, $1.86 \mathrm{~g} \mathrm{l}^{-1}$. Spirochaetes harvested from the culture vessel were used to test the hydrolysis of 68 different naphthylamide derivatives. The results of the peptidase activity tests were grouped according to the number of peptide bonds and the carboxy-terminal amino acid (Table 1). L-Alanine-related activities were only found by the use of the oligopeptides Ala-Phe-ProAla-2NA and Phe-Pro-Ala-2NA, indicating an elastaselike activity. In addition we found a chymotrypsin-like activity involving phenylalanine, tyrosine and tryptophan derivatives, a trypsin-like activity involving arginine and lysine derivatives and an iminopeptidase activity involving proline, hydroxyproline and pyrolidone derivatives.

\section{Arginine aminopeptidase activity}

Activity measurements with BAEE on the spirochaetes from the continuous culture were disturbed by the turbidity of the cell suspension in the incubation mixture. 
Table 1. Cell-bound peptidase activities of T. denticola ATCC 33520

T. denticola was grown in continuous culture and peptidase activities were tested by the Extended API System. +, Activity present; - , activity absent; $\bullet$, not tested. $a$, Elastase-like activity (substrates L-Ala-L-Phe-L-Pro-L-Ala-2NA and L-Phe-L-Pro-L-Ala2NA); $b$, chymotrypsin-like activity; $c$, iminopeptidase activity; $d$, trypsin-like activity.

\begin{tabular}{|c|c|c|c|}
\hline $\begin{array}{c}\text { Carboxy-terminal amino } \\
\text { acid in 2-naphthylamide } \\
\text { derivative }\end{array}$ & $\begin{array}{c}\text { Amino } \\
\text { peptidase }\end{array}$ & $\begin{array}{l}\text { Dipepti- } \\
\text { dase }\end{array}$ & $\begin{array}{c}\text { Oligo- } \\
\text { peptidase }\end{array}$ \\
\hline Glycine & - & - & - \\
\hline L-Alanine & - & - & $t^{a}$ \\
\hline L-Valine & - & - & $\bullet$ \\
\hline L-Leucine & - & - & - \\
\hline L-Isoleucine & - & - & $\bullet$ \\
\hline L-Phenylalanine & $t^{b}$ & - & $\bullet$ \\
\hline L-Proline & $+^{c}$ & $+^{c}$ & $t^{c}$ \\
\hline L-Serine & - & - & - \\
\hline L-Threonine & - & - & $\bullet$ \\
\hline L-Cysteine & - & $\bullet$ & $\bullet$ \\
\hline L-Methionine & - & - & - \\
\hline L-Glutamine & + & - & $\bullet$ \\
\hline L-Hydroxyproline & $t^{c}$ & - & - \\
\hline L-Tyrosine & $t^{b}$ & - & $\bullet$ \\
\hline L-Tyrptophane & $t^{b}$ & $t^{b}$ & $\bullet$ \\
\hline L-Pyrolidone & $+c$ & $\bullet$ & $\bullet$ \\
\hline L-Aspartate & - & - & - \\
\hline L-Glutamate & + & - & - \\
\hline L-Arginine & $+^{d}$ & $+^{d}$ & $+^{d}$ \\
\hline L-Lysine & $+^{d}$ & $t^{d}$ & - \\
\hline L-Histidine & - & - & - \\
\hline
\end{tabular}

The turbidity of the incubation mixture had no effect on fluorescence measurements using the fluorogenic substrate BAMC. A linear relation between fluorescence and time was observed with $T$. denticola ATCC 33520 densities $\left(\mathrm{OD}_{550}\right.$ ) ranging from 0.016 to 0.244 (Fig. 1 b). In the figure the absolute fluorescence values are shown. A linear relation was also observed with the naphthylamide derivative BANA, but only with spirochaete densities above $\mathrm{OD}_{550} 0 \cdot 188$ (Fig. 1a). The optimum BAMC concentration in the reaction mixture with $T$. denticola cells was $0.32 \mathrm{~mm}$; at higher concentrations a quenching of fluorescence was found (Fig. 2). The $\mathrm{pH}$ optimum for BAMC of $T$. denticola ATCC 33520 was pH 9.0 (Fig. $3 a$ ). The specific activity at pH 9.0 was $0.3 \pm 0.01 \mathrm{nmol} \mathrm{min}^{-1}(\mathrm{mg} \text { dry wt })^{-1}$ and was lowered in the presence of $0.5 \mathrm{mM}-\mathrm{HgCl}_{2}$ to $0.08 \pm 0.01 \mathrm{nmol} \mathrm{min}^{-1}$ (mg dry wt $)^{-1}$. The presence of 2 mM-DTT or -PMSF in the reaction mixture had no effect on the specific activity.

\section{Phenylalanine aminopeptidase activity}

Estimations of the phenylalanine aminopeptidase activities with PHENA were not successful due to the formation of a precipitate after addition of PHENA to the reaction mixture.

Incubating increasing densities of $T$. denticola cells with the fluorogenic substrate PHAMC gave some increase in fluorescence with time (Fig. 1c). The maximum increase in fluorescence was only 20 units after $80 \mathrm{~min}$ incubation. Finally, the phenylanaline peptidase activity was estimated with SPLP and gave an optimum at $\mathrm{pH} 8.5$ (Fig. $3 b$ ). The specific activity at $\mathrm{pH} 8.5$ was $36.6 \pm 0.7 \mathrm{nmol} \mathrm{min}^{-1}(\mathrm{mg} \text { dry } \mathrm{wt})^{-1}$. The activity was only slightly inhibited $\left[32.2 \pm 0.7 \mathrm{nmol} \mathrm{min}{ }^{-1}\right.$ (mg dry wt) $)^{-1}$ ] by the presence of $0.5 \mathrm{mM}-\mathrm{HgCl}_{2}$ and was not affected by PMSF. The use of the substrate SPLP did not allow a test with DTT.

\section{Proline aminopeptidase activity}

The naphthylamide derivative of benzyloxycarbonyl-Lproline, PRONA, gave a precipitate in the reaction mixture that prevented successful estimation of peptidase activity. The fluorogenic substrate PRAMC gave a linear increase in fluorescence with increasing $T$. denticola densities (Fig. 1d). The proline peptidase activity estimated with $0.163 \mathrm{mM}$-PRAMC showed an optimum at $\mathrm{pH} 8.5$ (Fig. $3 \mathrm{c}$ ). The specific activity at
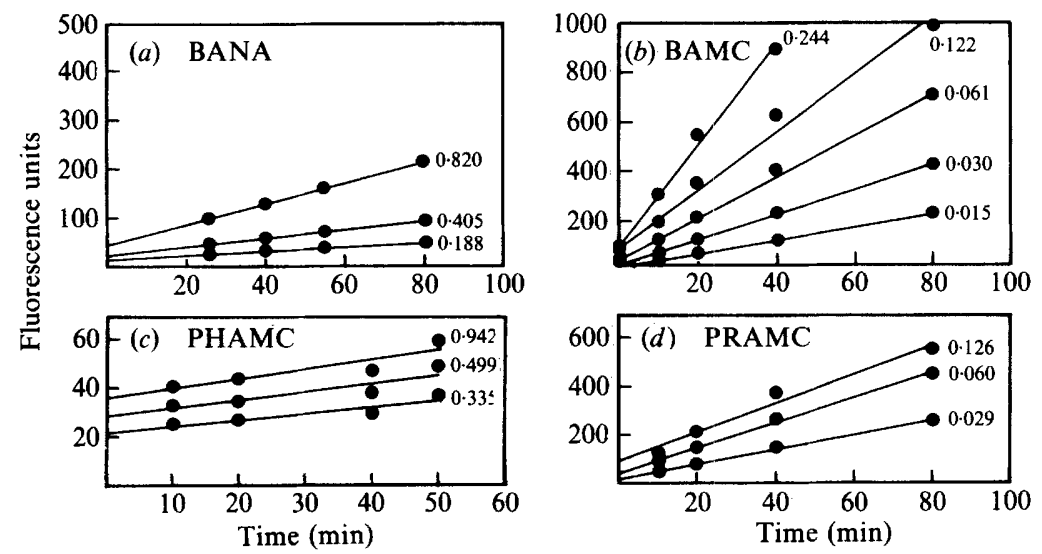

Fig. 1. Changes in fluorescence with time for different $T$. denticola ATCC 33520 densities $\left(\mathrm{OD}_{550}\right.$ indicated on the Figure itself) and amino acid derivatives in $0.1 \mathrm{M}$-Tris/HCl. (a) $2.5 \mathrm{~mm}$-BenzoylDL-arginine-2-naphthylamide (BANA) at pH 8.0; (b) 0-32 mM-benzoyl-DL-arginine-7-amido-4-methylcoumarin (BAMC) at $\mathrm{pH} 8.0$; (c) $0.32 \mathrm{mM}$-L-phenylalanine-7-amido-4-methylcoumarin (PHAMC) at pH 7.5; (d) 0.125 mM-L-proline-7-amido-4-methylcoumarin (PRAMC) at $\mathrm{pH} 7.5$. 


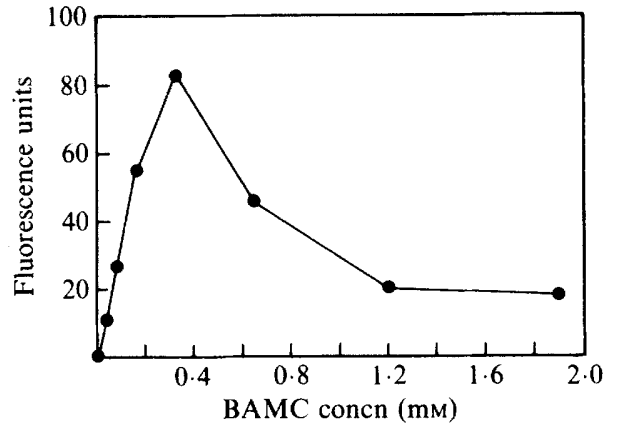

Fig. 2. Increase in fluorescence of benzoyl-DL-arginine-7-amido-4methylcoumarin (BAMC) after $45 \mathrm{~min}$ incubation with $T$. denticola ATCC $33520\left(\mathrm{OD}_{550} 0 \cdot 128\right)$ in $0 \cdot 1 \mathrm{M}$-Tris/ $\mathrm{HCl}$ buffer at $\mathrm{pH} 8.0$.

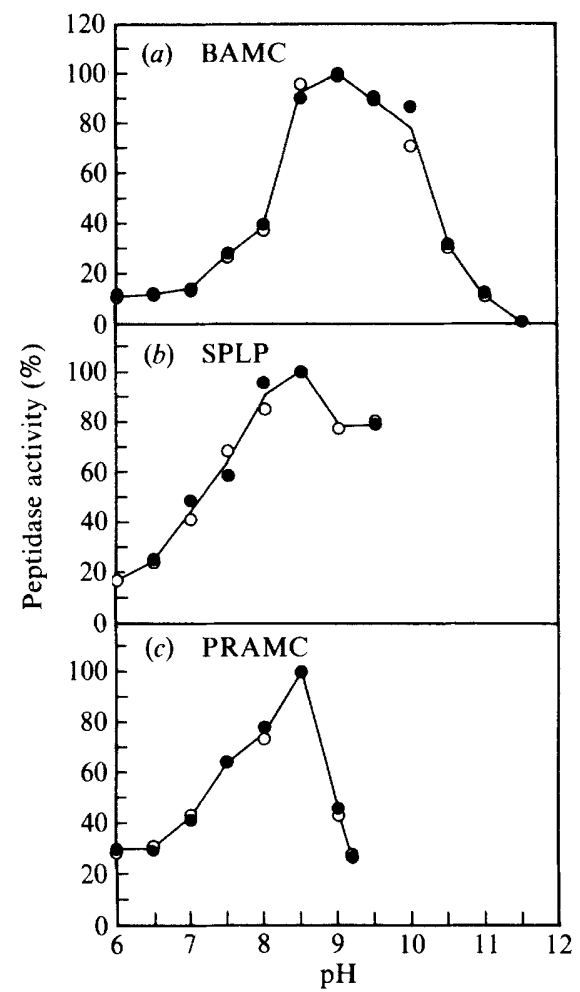

Fig. 3. pH optimum curves of (a) arginine peptidase with $0 \cdot 32 \mathrm{~mm}-$ benzoyl-DL-arginine-7-amido-4-methylcoumarin (BAMC), (b) proline peptidase with $0.125 \mathrm{mM}$-L-proline-7-amido-4-methylcoumarin (PRAMC) and (c) phenylalanine peptidase with $0.231 \mathrm{mM}-N$-succinylL-phenylalanyl-L-leucyl-L-phenylalanine-thiobenzyl ester (SPLP), obtained by incubating the derivatives with $T$. denticola ATCC 33520 $\left(\mathrm{OD}_{550} 0.5\right)$ in Teorell and Stenhagen's buffer. Results from two separate experiments $(O, O)$ are shown.

pH 8.5 was $1.5 \pm 0.02 \mathrm{nmol} \mathrm{min}^{-1}(\mathrm{mg} \text { dry wt) })^{-1}$; the activity was inhibited completely by $0.5 \mathrm{mM}-\mathrm{HgCl}_{2}$ and slightly stimulated by $2 \mathrm{mM}$-DTT $[2 \cdot 19 \pm 0.03 \mathrm{nmol}$ $\left.\min ^{-1}(\mathrm{mg} \text { dry } w t)^{-1}\right]$. PMSF had no effect on the proline aminopeptidase activity.

\section{Discussion}

The proteolytic activities of $T$. denticola have mainly been investigated with purified enzymes or extracts of sonicated spirochaetes (Mäkinen et al., 1986, 1987; Uitto et al., $1988 a, b$ ). In order to study the proteolytic activities which might play a role in tissue invasion and the persistence of $T$. denticola in the periodontal pocket, we investigated the extracellular peptidase activities of whole cells of $T$. denticola ATCC 33520 , grown in a low redox potential $(-385 \mathrm{mV})$, protein-rich medium without added carbohydrates at a mean generation time of $10 \mathrm{~h}$, which is within the limits of their natural habitat (Socransky \& Haffajee 1991; ter Steeg \& van der Hoeven, 1990). It is realized, but unknown for $T$. denticola, that the composition of the culture medium might play a role in the induction of proteases. Because of these culture restrictions, our observations are limited to the simultaneous measurement of different activities of cells from the same relatively fast-growing culture.

Under the above conditions, $T$. denticola ATCC 33520 cells showed at least four different extracellular peptidase activities.

The alanine peptidase or elastase-like activity is considered to be a virulence factor because of its broad specificity towards several structural proteins and its presence in periodontal pockets showing active destruction (Eley \& Cox, 1992). The activity in $T$. denticola ATCC 33520 was not observed with amino and dipeptide substrates but only with the carboxy-terminal alanine oligopeptide substrates, which indicates an endopeptidase activity that might be of nutritional importance, because numerous bacteria are dependent on small peptides for amino acid supply. Also, an effect of the test substrate may have played a role, since extension of the length of the peptide chain can lead to an increased sensitivity for peptidases (Zimmerman et al., 1977). A similar increase in sensitivity might have been responsible for the relative high chymotrypsin-like activity observed with SPLP (Harper et al., 1981).

A chymotrypsin-like enzyme has been isolated from $T$. denticola and shown to be attached to the outside of the cell envelope (Uitto et al., 1988b; Grenier et al., 1990). The enzyme has an optimum at $\mathrm{pH} 7.5$ and is inhibited by PMSF and $\mathrm{HgCl}_{2}$, indicating a serine protease with an active thiol group. The extracellular phenylalanine peptidase activity of $T$. denticola described here showed an optimum at $\mathrm{pH} 8.5$, was not inhibited by PMSF and only slightly affected by $\mathrm{HgCl}_{2}$. These differences cannot be explained by a substrate effect and indicate a difference in behaviour between the purified enzyme and the native cell-bound chymotrypsin-like activity, or the presence of more than one enzyme. 
The trypsin-like activity of $T$. denticola ATCC 33520 showed a clear optimum at $\mathrm{pH} 9.0$ with BAMC. A similar pH optimum was found with the substrate BAPNA by Mäkinen et al. (1986), who also indicated that the bulkier substrate BANA showed a less alkaline $\mathrm{pH}$ optimum. In addition, we found that BANA was a less sensitive substrate than BAMC. The trypsin-like activity of $T$. denticola has been stated to be a serine peptidase (Ohta et al., 1986; Mäkinen et al., 1986). The inhibition of the BAMC activity by $\mathrm{HgCl}_{2}$ in the present study indicates that at least a part of the cell-bound trypsin-like activity contains an active thiol group. The absence of a stimulatory effect by DTT might be due to the reduced state of cells freshly harvested from the culture (with a redox potential of $-385 \mathrm{mV}$ ). The cellbound trypsin-like activity of $T$. denticola seems to be related to more than one enzyme or to a single enzyme with a broad or varying activity. A benzoyl-arginine peptidase (BANA) with a iminopeptidase activity (PRONA) has been isolated from cell extracts of $T$. denticola (Mäkinen et al., 1987). For $P$. gingivalis, it has recently been shown that the membrane- or vesiclebound BANA activity is a thiol peptidase and not a trypsin-like enzyme (Shah et al., 1990). For these reasons, the proteolytic activities of $T$. denticola should be named after the substrate or the site of hydrolysis: for example, arginine peptidase activity instead of trypsin-like activity.

The cell-bound proline peptidase activity was totally blocked by the thiol reagent $\mathrm{HgCl}_{2}$, only slightly stimulated by DTT and resembled the iminopeptidase Enzyme III of $T$. denticola purified by Mäkinen et al. (1987). Enzyme III is considered to be a thiol peptidase with a $\mathrm{pH}$ optimum between $\mathrm{pH} 7.0$ and 7.5 for $N$-Lprolyl-2-naphthylamine. The more alkaline optimum, pH 8.5 , might be due to the test substrate, PRAMC, but is also in agreement with the indicated difference between the cell-bound and purified chymotrypsin-like activity.

With the exception of the difference in $\mathrm{pH}$ optimum, the cell-bound and extracellular activities of $T$. denticola ATCC 33520 resemble the purified enzymes of extracts of $T$. denticola, which have been shown to degrade a variety of proteins such as proline-rich salivary peptides, immunoglobulins, transferrin, $\alpha$-1-antitrypsin, fibrinogen and structural proteins (Uitto et al., 1988a, b; Grenier et al., 1990). Besides a role in nutrition, these cell-bound activities might play a role in tissue invasion by the spirochaetes. Migration of $T$. denticola through a basement-membrane-like material was found by Grenier et al. (1990). The alkaline optimum $\mathrm{pH}$ values of the investigated activities suggests that alkaline $\mathrm{pH}$ shifts in periodontal pockets (Eggert et al., 1991) will favour the destructive potential of $T$. denticola. Although tissue invasion by small spirochaetes including $T$. denticola is questionable (Mikx et al., 1990; Riviere et al., 1991), the different extracellular proteolytic activities of $T$. denticola are probably involved in the destruction process of the junctional epithelium in the anaerobic environment of the periodontal pocket, where spirochaetes including $T$. denticola frequently form the dominant group of bacteria.

We are thankful for the assistance of Kees van de Kieboom and Renatus Kaphipa in the preparation of the manuscript.

\section{References}

Armitage, G. C., Dickinson, W. R., Jenderseck, R. S., Levine, S. M. \& CHAMBERS, D. W. (1982). Relationship between the percentage of subgingival spirochetes and the severity of periodontal disease. Journal of Periodontology 53, 550-556.

Eggert, F. M., Drewell, L., Bigelow, J. A., Speck, J. E. \& GoLDNER, M. (1991). The pH of gingival crevices and periodontal pockets in children, teenagers and adults. Archives of Oral Biology 36, 233-238.

Eley, B. M. \& Cox, S. W. (1992). Cathepsin B, elastase-, tryptase-, trypsin- and dipeptidyl peptidase IV-like activities in gingival crevicular fluid: correlation with clinical parameters in untreated chronic periodontitis patients. Journal of Periodontal Research 27, 62-69.

FIEHN, N. E. (1986). Enzyme profiles from eight small-sized oral spirochetes. Scandinavian Journal of Dental Research 94, 132-140.

Grenier, D., UitTo, V. \& MCBRIDE, B. C. (1990). Cellular location of a Treponema denticola chymotrypsin-like protease and importance of the protease in migration through the basement membrane. Infection and Immunity 58, 347-351.

Harper, J. W., Ramirez, G. \& Powers, J. C. (1981). Reaction of peptide thiobenzyl esters with mammalian chymotrypsin-like enzymes: a sensitive assay method. Analytical Biochemistry 118, 382387.

Laughon, B. E., Syed, S. A. \& Loesche, W. J. (1981). API-ZYM system for identification of Bacteroides spp., Capnocytophaga spp. and spirochetes of oral origin. Journal of Clinical Microbiology 15, 97102.

Listgarten, M. A. \& Hellden, L. (1978). Relative distribution of bacteria at clinically healthy and periodontally diseased sites in humans. Journal of Clinical Periodontology 5, 115-132.

LOESCHE, W. J. (1988). The role of spirochetes in periodontal disease. Advances in Dental Research 2, 275-283.

Loesche, W. J., Giordano, J. \& Hujoel, P. P. (1990). The utility of the BANA test for monitoring anaerobic infections due to spirochetes (Treponema denticola) in periodontal disease. Journal of Dental Research 69, 1696-1702.

Mäkinen, K. K., Syed, S. A., MÄKInen, P. L. \& LoesChe, W. J. (1986). Benzoylarginine peptidase and iminopeptidase profiles of Treponema denticola strains isolated from the human periodontal pocket. Current Microbiology 14, 85-89.

MÄKINEN, K. K., SYED, S. A., MÄkInen, P. \& Loesche, W. J. (1987). Dominance of iminopeptidase activity in the human oral bacterium Treponema denticola A TCC 35405. Current Microbiology 14, 341-346.

Mikx, F. H. M. (1991). Comparison of peptidase, glycosidase and esterase activities of oral and non-oral Treponema species. Journal of General Microbiology 137, 63-68.

MIKX, F. H. M. \& DE JONG, M. H. (1987). Keratinolytic activity of cutaneous and oral bacteria. Infection and Immunity 55, 621-625.

Mikx, F. H. M., Maltha, J. C. \& van Campen, G. J. (1990). Spirochetes in early lesion of necrotizing ulcerative gingivitis, experimentally induced in beagle dogs. Oral Microbiology and Immunology 5, 86-89. 
Ohta, K., Makinen, K. K. \& Loesche, W. J. (1986). Purification and characterization of an enzyme produced by Treponema denticola capable of hydrolyzing synthetic trypsin substrates. Infection and Immunity 53, 213-220.

Reijntjens, F. M. J., Mikx, F. H. M., Wolters Lutgerhorst, J. M. L. \& MaLTHA, J. C. (1986). Adherence of oral treponemas and their effect on morphological damage and detachment of epithelial cells in vitro. Infection and Immunity 51, 642-647.

Riviere, G. R., Weisz, K. S., Adams, D. F. \& Denee Thomas, D. (1991). Pathogen-related oral spirochetes from dental plaque are invasive. Infection and Immunity 59, 3377-3380.

Saglie, R., Newman, M. G., Carranza, F. A. \& Pattison, G. L. (1982). Bacterial invasion of gingiva in advanced periodontitis in humans. Journal of Periodontology 53, 217-222.

Shah, H. N., Gharbia, S. E., Kowlessur, D., Wikie, E. \& BROCKLEHURST, K. (1990). Isolation and characterization of gingivain, a cysteine proteinase from Porphyromonas gingivalis strain W83. Biochemical Society Transactions 18, 578-579.

SOBER, H. A. (1970). CRC Handbook of Biochemistry. Selected Data for Molecular Biology. Cleveland, Ohio: Chemical Rubber Co.

SoCRANSKY, S. S. \& HafFaJEe, A. D. (1991). Microbial mechanisms in the pathogenesis of destructive periodontal disease: a critical assessment. Journal of Periodontal Research 26, 195-212.
TER STEEG, P. F. \& VAN DER HoEven, J. S. (1990). Growth stimulation of Treponema denticola by periodontal microorganisms. Antonie van Leeuwenhoek 57, 63-70.

Syed, S. A., Gusberti, F. A., Loesche, W. J. \& LANG, N. P. (1984). Diagnostic potential of chromogenic substrates for rapid detection of bacterial enzymatic activity in healthy and disease associated periodontal plaques. Journal of Periodontal Research 19, 618-621.

Syed, S. A., Salvado, S. L. \& Loesche, W. J. (1988). Enzyme profiles of oral spirochetes in RAPID-ANA system. Journal of Clinical Microbiology 26, 2226-2288.

Uitto, V. J., Chan, E. C. S. \& Chin Quee, T. (1986). Initial characterization of neutral proteinases from oral spirochetes. Journal of Periodontal Research 21, 95-100.

Uitto, V. J., Haapasalo, M., LaAkso, T. \& Salo T. (1988a). Degradation of basement membrane collagen by proteases from some anaerobic oral micro-organisms. Oral Microbiology and Immunology 3, 97-102.

Uitto, V. J., Grenier, D., Chan, E. C. S. \& MCBride, B. C. (1988b). Isolation of a chymotrypsin-like enzyme from Treponema denticola. Infection and Immunity 56, 2717-2722.

Zimmerman, M., Ashe, B., Yurewicz, E. C. \& Patel, G. (1977). Sensitive assays for trypsin, elastase, and chymotrypsin using new fluorogenic substrates. Analytical Biochemistry 78, 47-51. 